\title{
Extending the application domain of the model order reduction method in calculating the electrostatic field
}

\author{
Mochurad L. I. \\ Lviv Polytechnic National University, \\ 12 S. Bandera Str., 79013, Lviv, Ukraine
}

(Received 1 May 2019; Revised 18 August 2019; Accepted 20 August 2019)

\begin{abstract}
A problem of determining the electrostatic field formed by a set of charged electrodes has been considered. The details of the approximate solving of the Dirichlet problem have been given for the Laplace's equation in a substantially spatial formulation based on the use of the model order reduction method. The mathematical models have been improved and the problem of calculating the electrostatic field has been simplified, taking into account the present symmetry of electrodes positioning in electronic optics systems. For the eighth-order abstract group, three independent structures of the corresponding class of systems have been identified. The application domain of the model order reduction method based on finite-group theory for numerically solving integral equations has been extended by transforming the initial boundary-value problem not containing symmetry groups into two problems. The boundary surface of one of them has a finite symmetry group and the other allows for a sufficiently simple numerical solution. This simplification of the problem is aimed at improving the accuracy of computational methods, eliminating sources of instability of these methods, and speeding up computations. To confirm the efficiency of the proposed algorithm, a model problem of calculating the electrostatic field of a quadrupole lens has been considered. The example of its solving demonstrates all the advantages of the developed computational algorithm. A number of numerical experiments have been conducted. The electrostatic field of the corresponding planar approximations has been calculated to verify the validity of the obtained results.
\end{abstract}

Keywords: nanotechnology, electronic optics system, Laplace's equation, Abelian group of symmetry, Fourier transform, equipotential lines.

2000 MSC: 00A69, 05E15

UDC: 519.688

DOI: $10.23939 / \mathrm{mmc} 2019.02 .358$

\section{Introduction}

The rapid development and expansion of the field of nanotechnology put forward new requirements for electronic optics systems [1-4]. The last ones are used to form and control the bundles of charged electrodes. The quality of the formed beam affects the key parameters of devices which include electronic optics systems. For example, resolution of electron microscopes, energy characteristics of particle accelerators, precision of electronic vacuum lithography systems, noise characteristics of klystrons. Everywhere in these areas, there is a need to form a bundle of charges. They are not necessary to be electrons. In physics, there are examples of studying ions, collisions of various charged parts. To control them, an electrostatic or a magnetic field is used. In favour of the electrostatic field, we can say that we do not have energy losses for heating the coil. It is also known [5] that the Lorentz force consists of two components: the first corresponds to the electrostatic field and does not depend on the particle velocity; the second one depends on the velocity of the particle. Therefore, if we do not know this velocity, there is a need to use an electrostatic system. Designing such systems and controlling their parameters is based on complex mathematical calculations and simulation of processes of charges interaction with an electrostatic field created by a pair of cathode anodes and a system of "lenses" in the form of electrodes [6]. 
The basic mathematical model for such processes is the Laplace's equation along with the boundary conditions in relation to the electric potentials, which are set on the surfaces of the electrodes. Taking into account the complexity of three-dimensional geometry of electronic optics systems, presence of singularities in the nuclei of corresponding integral equations and formation of a large charge concentration at the boundaries of the electrodes, the exact solution of such an equation is a remarkable problem. In addition, for the correction of various aberrations in a bunch of charged particles, electrodes are used, which have complex geometry and symmetrically located relative to some axis.

\section{Literature review}

Among electrodes surfaces configurations of electronic optics systems, can be distinguished a class of surfaces possessing the Abelian group of the eighth order symmetry. This class includes so-called quadrupole systems [7]. The last ones are used in many electronic devices. Thus, lenses and their systems are the main parts of modern powerful electron microscopes and accelerators that play an important role in nuclear physics. Today, in most microprobes, which are in operation, use multiplet (systems of two, three or more) electrostatic quadrupole lenses [8].

With the help of electrodes "quadrupole lens" system type, which allows to create a spatial nonuniform electric field in the entire volume of electrodes system, carry out electrophysical purification of transformer oil from contaminants of various origin. The specified purification performance in real filtration plants can be obtained using parallel-coupled systems of spatial electrodes "quadrupole lens" type [9].

It is known [10] that each abstract Abelian group of finite order can be represented as a direct product of cyclic groups. Since the order of each group, which is a direct product, must be a divisor of the initial group order, then for the eighth order abstract groups there are three nonisomorphic structures: the structure of a group that has a representation in the form of a direct product of three cyclic groups of second order, the structure of a group that is represented by a direct product of the second and fourth order cyclic groups and the structure of the cyclic group of the eighth order. In this regard, in the boundary-value problems of electrodes surface, which possess the Abelian group of symmetry of the eighth order, three dif-

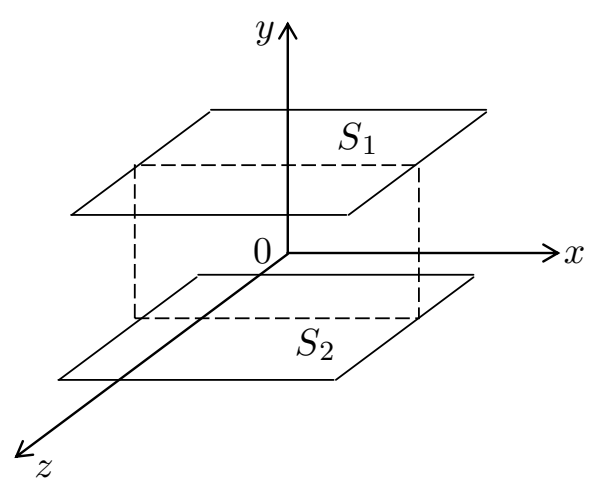

Fig. 1. Parallel capacitor. ferent cases can be distinguished. An example of the first case is the system of the surfaces electrodes configuration which is presented in Fig. 1. This system is studied in detail in the work $[11,12]$.

Having broken each plate $S_{1}$ and $S_{2}$ into four parts, it is obvious that our surface $S=S_{1} \cup S_{2}$ will have an Abelian group of symmetry of the eighth order $\left\{\tau_{i}\right\}_{i=1}^{8}$, which in turn is a direct product of the Abelian subgroups $\left\{e, \tau_{x}\right\},\left\{e, \tau_{y}\right\},\left\{e, \tau_{z}\right\}$, where $e$ is the identical transformation, and, $\tau_{x}$, $\tau_{y}, \tau_{z}$ is a mirror image of three pairs of orthogonal planes $\{y z\},\{x z\},\{x y\}$. That is, the elements of our group are the following linear transformations: $\tau_{1}=e, \tau_{2}=\tau_{x}, \tau_{3}=\tau_{y}, \tau_{4}=\tau_{x} \cdot \tau_{y}, \tau_{5}=\tau_{z}$, $\tau_{6}=\tau_{x} \cdot \tau_{z}, \tau_{7}=\tau_{y} \cdot \tau_{z}, \tau_{8}=\tau_{x} \cdot \tau_{y} \cdot \tau_{z}$.

An example of the second case is the quadrupole system presented in Fig. 2.

Electrode system, that is shown in Fig. 2 is presented in the form of a set of four smooth unlocked

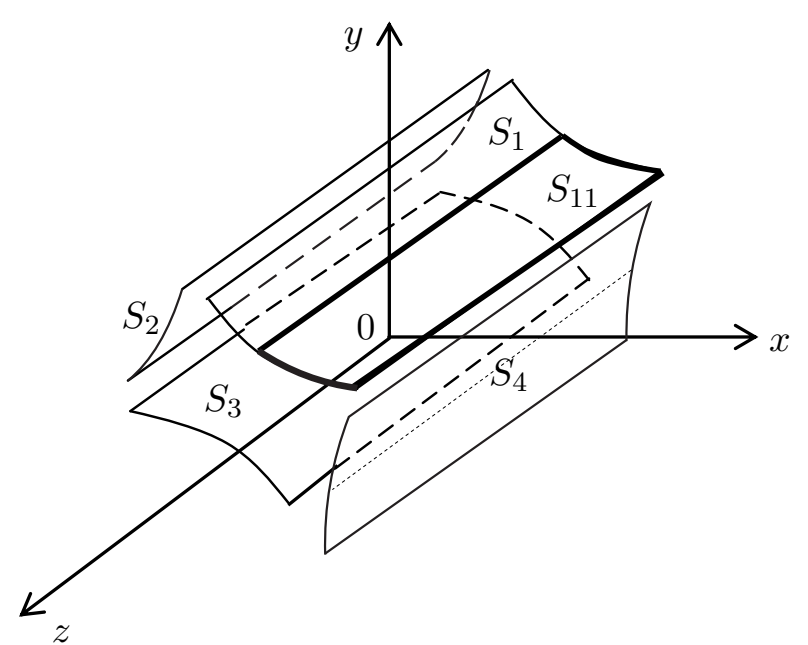

Fig. 2. Quadrupole lens. 
surfaces that do not have common points, is $S:=\cup_{i=1}^{4} S_{i}$. Having broken down each of its constituents $S_{i}$ into two congruent elements: $S_{i}:=\cup_{j=1}^{2} S_{i j}$, it is obvious that the surface will have an Abelian group of symmetry of the eighth order. The latter is a direct product of a cyclic group of fourth order, $\left\{e, \tau_{0}, \tau_{0}^{2}, \tau_{0}^{3}\right\}, \tau_{0}$ is a turn on an angle $\pi / 2$, and a second-order cyclic group $\{e, \tau\}, \tau$ is a mirror image.

Since the Laplace operator is invariant relative to the group of Euclidean space, and each finite group of surface symmetry in the Euclidean space is a subgroup of the Euclidean group, therefore, if the boundary surface has a finite group of symmetry, then the corresponding boundary value problem of the potential theory is similar to the group.

If the finite group of symmetries of the boundary value problem is commutative, then we can introduce the concept of convolution and the Fourier transform in this group [13]. Also, the boundary integral equation $[14,15]$, which corresponds to boundary value problems with "finite by group" symmetry space variables can be divided into two sets, one of which is finite and responsible group parameters corresponding to the second set of points with a boundary surface congruent components. In this case, the integral operator on a discrete variable can be considered in the case of a commutative group as a convolution operator on a finite group. The latter allows if using the Fourier transform on the symmetry group, to reduce the integral operator by the discrete variables to a diagonal form. This in turn corresponds to the transformation of the output integral equation given on the entire boundary surface to the $N$ integral equations given on one of the congruent components of the boundary surface, where $N$ is the order of the symmetry group of the boundary value problem.

In turn, transition from the original integral equation across the boundary surface to the integral equation on the congruent component in the computational relation allows, on the one hand, considerably reduce the amount of computing, but on the other hand, prevent numerical instability by reducing the order of matrix equations, which approximates the corresponding boundary integral equations in boundary-value problems with commutative symmetry group.

Thus, the methods of the theory of finite groups that can be used directly for numerical solving of integral equations in boundary-value problems are well investigated $[11,12,16,17]$. Areas of use of the method of reduction, in turn, are presented in papers [17-19]. This article shows that the scope of these methods can be greatly expanded on the basis of the transformation of the original boundary value problem, which does not contain the symmetry group (or contains such a group, but of a small order), to two problems, one of which contains a group of symmetries (contains a group symmetry of higher order), and the second - admits a fairly simple numerical solution.

\section{Formulation of the problem}

For the study, the following physical model is used: let the electrostatic field of the system of electronic optics be determined by the system $N-1$ of infinitely thin, ideally conductive electrodes $\left\{S_{i}\right\}$, which in their totality form a multiply connected surface:

$$
S^{(1)}:=\bigcup_{i=1}^{N-1} S_{i}, \quad \text { where } \quad S_{i} \bigcap S_{j}=\varnothing, \quad \text { when } i \neq j .
$$

To each electrode $S_{i} \in\left\{S_{i}\right\}$ the known potential, which is constant, is applied. Lets suppose that such system exists $S_{N}$, that $S:=\left(\cup_{i=1}^{N-1} S_{i}\right) \cup S_{N}=\cup_{i=1}^{N} S_{i}$, where $S_{N} \cap S_{i}=\varnothing$ when $i=1,2, \ldots, N-1$. Moreover the surface $S=S^{1} \cup S_{N}$ has a certain Abelian group $\left\{\tau_{k}\right\}, k=1,2, \ldots, N$, of symmetry $N$-th order.

We need to find a solution of the boundary value problem for the Laplace equation with boundary conditions on $S^{1}$ :

$$
\Delta U(x)=0, \quad x \in D, \quad x \notin S^{(1)}, \quad U(x)=f(x), \quad x \in S^{(1)},
$$


where $D$ is set of points of Euclidean space, $S^{(1)}$ is set of boundary points. Using the apparatus of integral equations, the problem (2) is reduced to the following operator equation:

$$
A \mu(x)=f(x), \quad x \in S^{(1)} .
$$

The possibility of preliminary calculation of electrostatic field distribution is an important task in designing the electrical and electronic equipment. Its complexity lies in the interaction between conductors, which manifests itself in the redistribution of charge on their surface. The definition of this redistribution is a key stage in calculation the resulting electrostatic field and determines the complexity of the task: the system of equations, which describes the distribution of charge a set of charged conductors, must take into account all conductors without exception.

\section{Method of reduction of the model order}

In this work it is shown that using the apparatus of the group theory, problem (2) can be reduced to the boundary value problem with the Abelian symmetry group of $N$-th order.

Let

$$
\begin{aligned}
& A_{11} \mu_{1}(x) \quad+\ldots+A_{1, N-1} \mu_{N-1}(x)=f_{1}(x) \\
& \ldots \ldots \ldots \ldots \ldots \ldots \ldots \ldots \ldots \ldots \ldots \ldots \ldots \ldots \ldots \\
& A_{N-1,1} \mu_{1}(x)+\ldots .
\end{aligned}
$$

is a partition of the integral equation (3), which corresponds to the partition (1) of the surface $S^{(1)}$. There $\mu(x)$ is surface charge density, $f(x)$ is given limit value of the potential, $\mu_{i}(x)$ and $f_{i}(x) i=$ $1,2, \ldots, N-1$ are narrowing $\mu(x)$ and $f(x)$ on $S_{i}, i=1,2, \ldots, N-1$. Herewith

$$
A_{i j} \rho_{j}=\int_{S_{j}} \frac{\rho_{j}(x)}{|x-y|} d S_{j}, \quad y \in S_{i}, x \in S_{j}, i, j=1,2, \ldots, N-1
$$

there $|x-y|$ is euclidean distance between points $x$ and $y$.

Now turn from equations (4) to the equations of the next form:

$$
\begin{aligned}
& A_{11} \mu_{1}(x)+\ldots+A_{1, N-1} \mu_{N-1}(x)+A_{1 N} \mu_{N}(x)=f_{1}(x), \\
& A_{N-1,1} \mu_{1}(x)+\ldots+A_{N-1, N-1} \mu_{N-1}(x)+A_{N-1, N} \mu_{N}(x)=f_{N-1}(x), \\
& A_{N 1} \mu_{1}(x)+\ldots+A_{N, N-1} \mu_{N-1}(x)+A_{N N} \mu_{N}(x)=f_{N}(x) \text {. }
\end{aligned}
$$

Obviously, that the system (5) corresponds to the boundary-value problem for the Laplace equation

$$
\Delta U(x)=0, \quad x \in D, x \notin S, \quad U(x)=f(x), x \in S,
$$

with Abelian group of symmetry of $N$-th order, that is, the boundary value problem (2) reduces to the boundary value problem (6), whose boundary surface of electrodes has an Abelian symmetry group of, if function $f_{N}(x)$ is defined. We will show, that $f_{N}(x)$ can be determined from the condition that $\mu_{N}(x)=0$. To do this, let's move on from the basis $\left\{\mu_{i}(x)\right\}, i=1,2, \ldots, N$, in the basis $\left\{\mu_{i}^{\prime}(x)\right\}$, $\mu_{i}^{\prime}(x)=\mu_{i}\left(\tau_{i}^{-1} x\right), i=1,2, \ldots, N$, and designate operator matrix as $\left\|A_{i j}^{\prime}\right\|_{i, j=1}^{N}$, which corresponds in the basis $\left\{\mu_{i}^{\prime}(x)\right\}$ to matrix $\left\|A_{i j}\right\|_{i, j=1}^{N}$ of equations system (5). In accordance, if $\left\|F_{i j}\right\|_{i, j=1}^{N}$ is the Fourier transform matrix for the symmetry abelian group which has a surface $S$, then in the basis $\bar{\mu}_{i}^{\prime}(x)=\sum_{j=1}^{N} F_{i j} \mu_{j}^{\prime}(E)$ the matrix $\left\|A_{i j}^{\prime}\right\|$ acquires a diagonal form, and equation (5) goes over to the equation

$$
A_{i} \mu_{i}^{\prime}(x)=\bar{f}_{i}^{\prime}(x), \quad x \in S_{i}, \quad i=1,2, \ldots, N,
$$


where $A_{i}=\bar{A}_{i i}^{\prime}=\sum_{k, m=1}^{N} F_{i k} A_{k m}^{\prime} \hat{F}_{m i}$, and $\left\|\hat{F}_{i j}\right\|_{i, j=1}^{N}$ is the matrix of inverse Fourier transform. Accordingly, equation (7) can be rewritten in the form

$$
A_{i} \bar{\mu}_{i}^{\prime}(x)=\sum_{j=1}^{N-1} F_{i j} f_{j}^{\prime}(x)+F_{i N} f_{N}^{\prime}(x) .
$$

From the last equality it follows that

$$
\bar{\mu}_{i}^{\prime}(x)=\sum_{j=1}^{N-1} F_{i j} A_{i}^{-1} f_{j}^{\prime}(x)+A_{i}^{-1} F_{i N} f_{N}^{\prime}(x) .
$$

Because $\mu_{N}^{\prime}(x)=\sum_{i=1}^{N} \hat{F}_{N i} \bar{\mu}_{i}^{\prime}(x)$, then equality (8) takes the following form

$$
\mu_{N}^{\prime}(x)=\sum_{i=1}^{N} \sum_{j=1}^{N-1} \hat{F}_{N i} F_{i j} A_{i}^{-1} f_{j}^{\prime}(x)+\left(\sum_{i=1}^{N} \hat{F}_{N i} F_{i N} A_{i}^{-1}\right) f_{N}^{\prime}(x) .
$$

It is known, that $\mu_{N}(x)=0$ then $\mu_{N}^{\prime}(x)=0$, therefore

$$
f_{N}^{\prime}(x)=-\left(\sum_{i=1}^{N} \hat{F}_{N i} F_{i N} A_{i}^{-1}\right)^{-1}\left[\sum_{i=1}^{N} \sum_{j=1}^{N-1} \hat{F}_{N i} F_{i j} A_{i}^{-1} f_{j}^{\prime}(x)\right] .
$$

Since $f_{N}(x)=f_{N}^{\prime}\left(\tau_{N} x\right)$, where $\left\{\tau_{k}\right\}, k=1,2, \ldots, N$ are elements of the symmetry group, which has a surface $S$, then from (9) we can calculate the function $f_{N}(x)$, and by solving the problem (2) go to the solution of the boundary value problem (6), where the boundary surface of the electrodes has an Abelian group of $N$-th order symmetry.

It should be noted that in numerical implementation, this method will only be effective when the surface area $S^{(1)}$ is larger than the surface area $S \backslash S^{(1)}$.

\section{Numerical experiments}

Without reducing the universality, for example, consider the task of calculation the electrostatic field of the electronic optics system presented in Fig. 2. As shown above, the surface of the electrodes of a quadrupole lens has an Abelian group of the eighth order symmetry. We will assume that one of the eight congruent components of the surface is absent, for example, $S_{42}$. Then the relation (8) will look like

$$
\bar{\mu}_{i}^{\prime}(x)=\mu_{i}^{(1)}(x)+\mu_{i}^{(2)}(x),
$$

where $\mu_{i}^{1}(x)=A_{i}^{-1}(x) f_{i}^{1}(x), \mu_{i}^{2}(x)=A_{i}^{-1}(x) f_{i}^{2}(x), i=1,2, \ldots, 8$. Then using the Fourier transform matrix

$$
\left(F_{i j}\right)_{i, j=1}^{8}=\left(\begin{array}{rrrrrrrr}
1 & 1 & 1 & 1 & 1 & 1 & 1 & 1 \\
1 & -1 & -1 & 1 & 1 & -1 & -1 & 1 \\
1 & 1 & -1 & 1 & -1 & 1 & -1 & -1 \\
1 & -1 & 1 & 1 & -1 & -1 & 1 & -1 \\
1 & 1 & 1 & -1 & 1 & -1 & -1 & -1 \\
1 & -1 & -1 & -1 & 1 & 1 & 1 & -1 \\
1 & 1 & -1 & -1 & -1 & -1 & 1 & 1 \\
1 & -1 & 1 & -1 & -1 & 1 & -1 & 1
\end{array}\right)
$$

for $f_{i}^{1}(x)$ can be written

$$
f_{1}^{(1)}=f_{1}^{\prime}+f_{2}^{\prime}+f_{3}^{\prime}+f_{4}^{\prime}+f_{5}^{\prime}+f_{6}^{\prime}+f_{7}^{\prime},
$$

Mathematical Modeling and Computing, Vol. 6, No. 2, pp. 358-366 (2019) 


$$
\begin{aligned}
& f_{2}^{(1)}=f_{1}^{\prime}-f_{2}^{\prime}-f_{3}^{\prime}+f_{4}^{\prime}+f_{5}^{\prime}-f_{6}^{\prime}-f_{7}^{\prime}, \\
& f_{3}^{(1)}=f_{1}^{\prime}+f_{2}^{\prime}-f_{3}^{\prime}+f_{4}^{\prime}-f_{5}^{\prime}+f_{6}^{\prime}-f_{7}^{\prime}, \\
& f_{4}^{(1)}=f_{1}^{\prime}+f_{2}^{\prime}+f_{3}^{\prime}+f_{4}^{\prime}-f_{5}^{\prime}-f_{6}^{\prime}+f_{7}^{\prime}, \\
& f_{5}^{(1)}=f_{1}^{\prime}+f_{2}^{\prime}+f_{3}^{\prime}-f_{4}^{\prime}+f_{5}^{\prime}-f_{6}^{\prime}-f_{7}^{\prime}, \\
& f_{6}^{(1)}=f_{1}^{\prime}-f_{2}^{\prime}-f_{3}^{\prime}-f_{4}^{\prime}+f_{5}^{\prime}+f_{6}^{\prime}+f_{7}^{\prime}, \\
& f_{7}^{(1)}=f_{1}^{\prime}+f_{2}^{\prime}-f_{3}^{\prime}-f_{4}^{\prime}-f_{5}^{\prime}-f_{6}^{\prime}+f_{7}^{\prime}, \\
& f_{8}^{(1)}=f_{1}^{\prime}-f_{2}^{\prime}-f_{3}^{\prime}-f_{4}^{\prime}-f_{5}^{\prime}+f_{6}^{\prime}+f_{7}^{\prime},
\end{aligned}
$$

and $f_{i}^{2}(x)$ can be represented as

$$
f_{1}^{(2)}(x)=f_{2}^{(2)}(x)=f_{7}^{(2)}(x)=f_{8}^{(2)}(x)=f_{8}^{\prime}, \quad f_{3}^{(2)}(x)=f_{4}^{(2)}(x)=f_{5}^{(2)}(x)=f_{6}^{(2)}(x)=-f_{8}^{\prime},
$$

where taking into account $(9), f_{8}^{\prime}(x)$ takes the form

$$
\begin{gathered}
f_{8}^{\prime}(x)=\left[A_{1}^{-1}+A_{2}^{-1}+A_{3}^{-1}+A_{4}^{-1}+A_{5}^{-1}+A_{6}^{-1}+A_{7}^{-1}+A_{8}^{-1}\right]^{-1} \hat{\mu}(x), \\
\hat{\mu}(x)=\left[\rho_{1}^{(1)}(x)+\rho_{2}^{(1)}(x)-\rho_{3}^{(1)}(x)-\rho_{4}^{(1)}(x)-\rho_{5}^{(1)}(x)-\rho_{6}^{(1)}(x)+\rho_{7}^{(1)}(x)+\rho_{8}^{(1)}(x)\right] .
\end{gathered}
$$

In this work the program is presented for calculating the electrostatic field of the system of electronic optics in Fig. 2, with the presence of eight and seven congruent components. As a result, a number of numerical experiments were conducted for arbitrary limit values of potential. It is taken into account that the boundary surface has an Abelian group of the eighth order symmetry. During numerical solving of integral equations the most economical method of collocation is used in the case of piecewise constant approximation of the required charge distribution density. The system of linear algebraic equations is solved by the Gauss' method [20]. To verify the reliability of the results, the electrostatic field is calculated based on the corresponding flat approximations [18].

\section{Analysis of results}

It is known that the electrostatic field is characterized by tension and potential at each point. The visualization of the results of simulation of the electrostatic field of a quadrupole lens (see Fig. 2) with the use of the above-described algorithm is represented by the distribution of the equipotential lines. Usually, in this way, potential fields are experimentally studied, and lines of tension are constructed as orthogonal lines to the equipotential ones.

In Fig. 3 it is shown the equipotential lines of studied electronic optics system, in the presence of eight congruent components - cases $\boldsymbol{a}, \boldsymbol{b}$ and seven congruent components - cases $\boldsymbol{c}, \boldsymbol{d}$. Limit values of potential on electrodes: case $\boldsymbol{a}-f_{1}=f_{2}=0.1, f_{3}=f_{4}=0.2, f_{5}=f_{6}=0.3, f_{7}=f_{8}=0 ; \boldsymbol{b}-$ $f_{1}=f_{2}=0.1, f_{3}=f_{4}=0.2, f_{5}=f_{6}=0.3, f_{7}=0 ; \boldsymbol{c}-f_{1}=f_{2}=1, f_{3}=f_{4}=-1, f_{5}=f_{6}=1$, $f_{7}=f_{8}=-1 ; \boldsymbol{d}-f_{1}=f_{2}=1, f_{3}=f_{4}=-1, f_{5}=f_{6}=1, f_{7}=-1$.

Obtained in Fig. 3 results correspond to the physics of investigated phenomenon.

If the surfaces of the charged electrodes are infinitely long cylindrical, generatrices of which are infinitely thin filaments parallel to one of co-ordinate axes and equally charged on length, then in a cut with an arbitrary plane, perpendicular to this axis, some aggregate of the open-circuit arcs appears. Then the value of potential of the researched field in the arbitrary point of space does not depend on one co-ordinate. Therefore, the examined spatial task can be interpreted as flat [21].

It is also noticed [18] that under predominance of one geometrical component surface over the other ones the value of potential in her transversal cuts close to central changes are small. It allows 

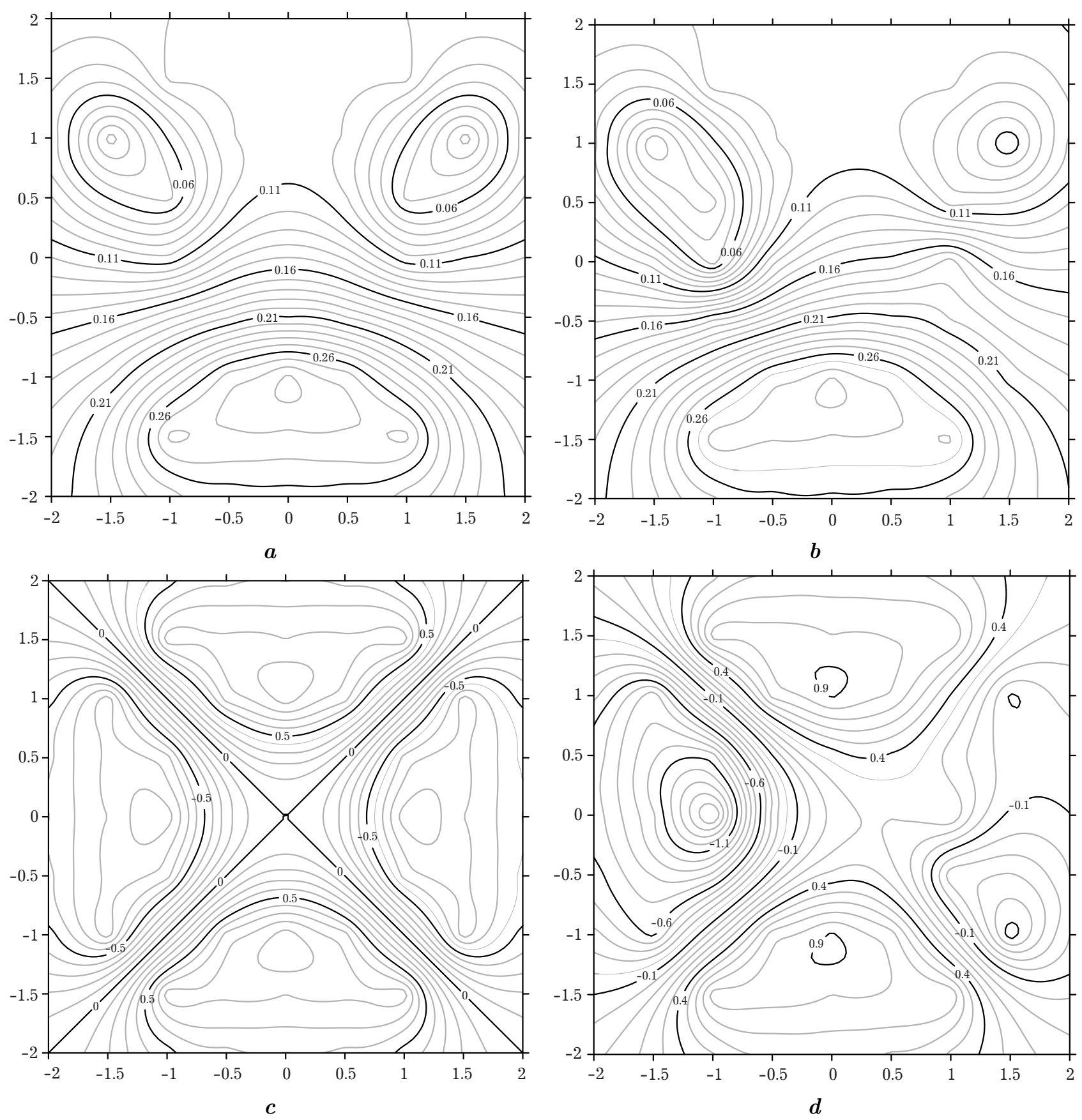

Fig. 3. Lines of distribution of equal potential.

us to draw a conclusion that for establishing the high-quality representation of the field in the central transversal cuts of the electron-optical systems, under condition of satisfying boundary surfaces of the geometrical properties shown above, it is possible to limit the research only of the flat cuts of spatial constructions. It allows to interpret a spatial task as flat.

Error between the calculated potential values, obtained in the solution of spatial problems and corresponding planar approximations in the case of a two-fold increase in predominance of one component of the surface over other is approximately $0.1 \%$. Usage of the proposed approach has reduced the cost of computer RAM (random access memory) by about 5 times, and processor time - about 12 times. The last one is due to the fact that instead of matrix dimension $7 M \times 7 M$ eight dimensional matrices are reversed $M \times M$ and one matrix of the same size is rotated. 


\section{Conclusion}

In this paper, the scope of application of method for model order reducing is extended in the case, when the boundary surface of the electrodes does not have a symmetry group, or owns such a group, but in a lesser order. It is shown, that the initial boundary-value problem can be represented in the form of two problems, one of which is a problem with an Abelian group of finite-order symmetry, and the other allows effective numerical solving. This allowed us: to reduce the costs of computer memory and processor time; to get high-accuracy numerical resolution of spatial problem and at the same time to avoid the instability of the calculations. As a result, calculation of potential fields on the basis of the proposed algorithm gives an opportunity to control a bunch of charged electrodes with high accuracy, which is important in designing the electronic optics systems.

As an example, the spatial problem of electrostatics is considered for the model of electronic optics system - quadrupole lens. The conducted study illustrates the possibility of generalization of the proposed computing algorithm in the case where the boundary surface of the electrodes does not have an Abelian finite-order symmetry group.

[1] Salerno M., Landoni P., Verganti R. Designing foresight studies for Nanoscience and Nanotechnology (NST) future developments. Technological Forecasting and Social Change. 75 (8), 1202-1223 (2008).

[2] Nikulainen T., Palmberg C. Transferring science-based technologies to industry - Does nanotechnology make a difference? Technovation. 30 (1), 3-11 (2007).

[3] Antonyuk V. S., Timchik G. S., Vercanova O. V., et.al. Microscopy in nanotechnology: monograph. Kyiv, NTUU "KPI" (2014), (in Ukrainian).

[4] Okayawa S. A new type of quadrupole lens for electron-beam lithography. Nuclear Instruments and Methods in Physics Research Section A: Accelerators, Spectrometers, Detectors and Associated Equipment. 298 (1-3), 488-495 (1990).

[5] Garkusha I. P., Gorbaruk I. I., Kurinnuj V.P., et. al. General course of physics. Collection of tasks. Kyiv, Technics (2003), (in Ukrainian).

[6] Romanenko A. V., Ostudin B. A. Calculation of the motion of a charged particle in an electrostatic field, taking into account the spatial charge. Theoretical Electrical Engineering. 59, 87-103 (2002), (in Ukrainian).

[7] Hawkes P., Kasper E., Kirkland A. Principles of Electron Optics. Applied Geometrical Optics. Vol. 2. 2nd Edition, Academic Press (2017).

[8] Abramovich S. N., Zavyalov N. V., Zvenigorod A. G., Ignatiev I. G., Magilin D. V., Mel'nik K. I., Ponomarev A. G. Optimization of the probe-forming system of a nuclear scanning microprobe based on the EGP-10 electrostatic charge-exchange accelerator. Journal of Technical Physics. 75, 6-12 (2005), (in Russian).

[9] Gladkov V. S., Guchenko O. A., Shesterikov O. V. Doslidzhennya experimental installation of the installation of purified transformer oil. Bulletin of NTU "KPI". 39, 46-50 (2009), (in Ukrainian).

[10] Serre J.-P. Linear representations of finite groups. Moscow, RHD (2003), (in Russian).

[11] Mochurad L., Harasym Y., Ostudin B. Maximal Using of Specifics of Some Boundary Problems in Potential Theory After Their Numerical Analysis. International Journal of Computing. 8, 149-156 (2009).

[12] Mochurad L. Method of reduction model for calculation of electrostatic fields of electronic optics systems. Radio Electronics Computer Science Control. 48 (1), 29-40 (2019).

[13] Sergienko A. B. Digital signal processing: studies, allowance. SPb., Peter (2003), (in Russian).

[14] Melnik I. V. Using the method of integral equations for numerical simulation of the optical properties of diode systems of a high-voltage glow discharge with an anode plasma. Proceedings of the Institute of Applied Mathematics and Mechanics of the National Academy of Sciences of Ukraine. 6, 80-85 (2001).

[15] Chapko R., Tomas Johansson B., Savka Yu. On the use of an integral approach for the numerical solution of a Cauchy problem for Laplace equation in a doubly conneted planar domain. Inverse Problems in Science and Engineering. 22 (1), 130-149 (2014). 
[16] Mochurad L. I., Pukach P. Ya. An Efficient Approach to Calculating the Electrostatic Field of a Quadrupole. Edition of Kherson National Technical University. 62, 155-165 (2017), (in Ukrainian).

[17] Zakharov Y., Safronov S., Tarasov P. The Abelian groups of finite order in numeral analysis of linear boundary tasks of the theory of potential. Journal of computational mathematics and mathematical physics. 32, 40-58 (1992), (in Russian).

[18] Mochurad L.I., Ostudin B. A. Flat variant of substantially spatial problem of electrostatics and some aspects of its solution, related to specifics of input information. Journal of Numerical and Applied Mathematics. 2 (105), 98-110 (2011).

[19] Verlan A. F., Dyachuk A. A., Palagin V. V. Methods of mathematical reduction of models dynamic systems. Kiev, Naukova Dumka (2019), (In Russian).

[20] Balandin M. Yu., ShurinaE. P. The Methods for Solving High-dimensional SLAE. Novosibirsk, NSTU (2000), (in Russian).

[21] Vladimirov V.S. Equation of mathematical physics. Moscow, Science (1981).

\title{
Розширення області застосування методу редукції порядку моделі під час розрахунку електростатичного поля
}

\author{
Мочурад Л. І. \\ Національний університет "Львівсъка політехніка", \\ вул. С. Бандери, 12, Лъвів, 79013, Україна
}

Розглянуто проблему визначення електростатичного поля, утвореного сукупністю заряджених електродів. Наведено деталі наближеного розв'язування задачі Діріхле для рівняння Лапласа в суттєво просторовому формулюванні на основі використання методу редукції порядку моделі. Удосконалено математичні моделі та спрощено задачу розрахунку електростатичного поля з урахуванням симетрії розташування електродів у системах електронної оптики. Для абстрактної групи восьмого порядку виділено три незалежні структури відповідного класу систем. Розширено область використання методу редукції порядку моделі на основі теорії скінченних груп у разі чисельного розв'язування інтегральних рівнянь зведенням вихідної крайової задачі, яка не містить групи симетрії, до двох. Гранична поверхня однієї з них володіє скінченною групою симетрії, а друга - допускає достатньо просте чисельне розв'язування. Таке спрощення задачі спрямоване на підвищення точності обчислювальних методів, усунення джерел нестійкості цих методів та пришвидшення обчислень. Для підтвердження дієвості запропонованого алгоритму розглянуто модельну задачу розрахунку електростатичного поля квадрупольної лінзи. На прикладі її розв'язування продемонстровано усі переваги розробленого обчислювального алгоритму. Проведено чисельні експерименти. Для перевірки достовірності отриманих результатів розраховано електростатичне поле відповідних плоских наближень.

Ключові слова: нанотехнологї̈, система електронної оптики, рівняння Лапласа, абелева група симетріӥ, перетворення Фур'є, еквіпотенціальні лінії.

2000 MSC: 00A69, 05E15

УДК: 519.688 